\title{
How Inclusive are the Local Economic Impacts of Social Protection in Uganda?
}

\author{
Maria Klara Kuss $^{1} \cdot$ Franziska Gassmann $^{1} \mathbb{D} \cdot$ Firminus Mugumya $^{2}$
}

Accepted: 21 October 2021 / Published online: 15 November 2021

(c) The Author(s) 2021

\begin{abstract}
Inclusive growth and development are essential for the sustainability of poverty reduction and growth. Social protection has been promoted as part of the inclusive growth and development agenda by emphasising the positive impacts of social transfers on people's participation in economic processes. However, the focus on the positive economic impacts of social transfers has led to the neglect of concerns regarding inequality of opportunity. Taking the case of Uganda's Senior Citizens Grant, this paper critically assesses how inclusive the impacts of social transfers are on economic processes. This is done by examining the extent to which local economic structures interplay with the impacts of the Grant. Based on a qualitative case study design, the analysis reveals that the scheme has unwittingly reinforced spatial patterns of economic exclusion and disadvantage. Recipients in remote areas are more likely to stay or fall back into poverty compared to people in integrated areas. For social transfers to contribute to inclusive growth and development for all, it will be vital to invest in complementary development interventions in economically disadvantaged areas.
\end{abstract}

Keywords Inclusive growth and development $\cdot$ Social protection $\cdot$ Social cash transfers $\cdot$ Local economic impacts · Inequality of opportunity $\cdot$ Sub-Sahara Africa Uganda

\section{Résumé}

La croissance et le développement inclusifs sont essentiels pour une réduction durable de la pauvreté et pour une croissance pérenne. La protection sociale a été érigée en bonne pratique dans le cadre du programme de croissance et de développement inclusifs en mettant l'accent sur l'impact positif des transferts sociaux sur la participation des personnes à l'activité économique. Cependant, l'accent mis sur cet impact

Franziska Gassmann

Franziska.gassmann@maastrichtuniversity.nl

1 UNU-MERIT, Maastricht University, PO Box 616, 6200 MD Maastricht, The Netherlands

2 Makerere University, Kampala, Uganda

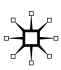


économique positif a conduit à négliger les préoccupations concernant l'inégalité des chances. Cet article prend le cas de l'allocation Personnes âgées en Ouganda et fait une évaluation critique du degré d'inclusivité de l'impact des transferts sociaux sur les activités économiques. Pour cela, nous examinons la mesure dans laquelle les structures économiques locales interagissent avec l'impact de l'allocation. À l'aide d'une méthodologie qualitative d'étude de cas, l'analyse révèle que le programme a involontairement renforcé les schémas spatiaux d'exclusion et de désavantage économiques. Les bénéficiaires du programme qui vivent dans des zones reculées sont plus susceptibles de rester ou de retomber dans la pauvreté par rapport aux personnes vivant dans des zones intégrées. Si l'on souhaite que les transferts sociaux contribuent à une croissance et un développement inclusifs pour toutes et tous, il sera essentiel d'investir dans des interventions de développement complémentaires dans les zones économiquement défavorisées.

\section{Introduction}

The need for inclusive growth and development has become increasingly recognised in international development, reflecting growing concerns about rising inequalities despite economic growth. Inclusiveness is concerned with the expansion of equal opportunities to all members of society in order to eradicate poverty, reduce inequalities, and sustain growth. It focuses less on the extent to which poor people benefit from growth but rather on the extent to which poor people participate and contribute to growth (De Haan 2015; Kanbur and Rauniyar 2010).

Promoters of social protection have put considerable effort into establishing a developmental rationale for social protection, which resonates with the inclusive growth agenda. In Africa and elsewhere, international donors have particularly focused on promoting social cash transfers (SCTs) as policy instruments to enhance people's participation in economic processes and thereby reduce poverty. These efforts have been supported by numerous impact assessments offering much evidence on the effectiveness of these interventions in achieving a range of positive economic outcomes (see Bastagli et al. 2016 for an overview). It has been demonstrated that SCTs can enhance the economic participation of recipients and their families, as well as improve the economic opportunities of non-recipients through increased local demand for goods and services as well as increased supply and availability of local economic structures (Rougier et al. 2018; Barrientos 2012; Alderman and Yemtsov 2014; Davis et al. 2012, 2016).

While this evidence base has positioned social protection within the inclusive growth and development agenda, the desire to find positive evidence has paradoxically resulted in the neglect of concerns around inequalities of opportunities. Most policy evaluations focus on the poor as a homogeneous category ignoring intra-group differences that influence people's ability to participate in economic processes. If horizontal inequalities are acknowledged in current social protection literature, the focus is predominantly on indicators such as gender and age, which tend to inform targeting debates (Seekings 2008; Amuzu et al. 2010; Jones and Holmes 2011). The importance of location with its local economic structures, such as 
the available infrastructure, opportunities for work or the presence of markets, has largely been ignored in social protection evaluations, even though local economic structures are likely to condition the economic impacts of social protection (see Ravallion 2009; Krugman 1991). Local economic structures can be thought of as community-level factors that influence how people can engage in economic processes (Barrientos 2012).

Given the ongoing expansion of SCTs in many African countries, the relevance of local economic structures for SCT-driven economic growth processes needs to be examined and understood. The objective of this article is to analyse the extent to which local economic structures interplay with SCT-related economic outcomes using the case of Uganda's flagship SCT programme, the Senior Citizens Grant (SCG). Uganda constitutes a particularly adequate country to explore the inclusiveness of local economic impacts of SCTs across different locations. The country is characterised by high levels of spatial inequality, reflected in the rural-urban divide, and regional and sub-regional disparities in terms of poverty ${ }^{1}$ (Uganda Bureau of Statistics 2017) and access to infrastructure and services, such as transportation, financial services, and markets (World Bank 2012a; DRT 2013). The Government of Uganda has committed itself to spatially balanced and equitable development and embraced the inclusive growth agenda as a core feature of their National Development Plan (Republic of Uganda 2015).

The SCG is particularly interesting because it is expected "to reduce poverty and socio-economic inequalities for inclusive development” (MGLSD 2015, p. 28). The SCG is a SCT intervention for Ugandans above the age of $65,{ }^{2}$ transferring UGX 50,000 (ca. USD 16) every two months (MGLSD 2016). The specific aim of the intervention is to reduce chronic poverty and improve the life chances of the target group. In 2011, the scheme was initiated as a five-year pilot programme in 15 districts. In 2015, the Ugandan government decided to gradually expand the SCG nationwide, adding five additional districts each financial year. ${ }^{3}$ In early 2020, it reached 169,342 recipients and was subsequently rolled out to an additional 200,000 people across all 135 districts (Doyle et al. 2021, p. 2). Although the scheme is targeted at older people, which may be more likely to be physically labour-constrained, existing impact studies have confirmed a wide range of positive economic impacts (OPM 2015, 2016; Ibrahim and Namuddu 2014; Bukuluki and Watson 2012; Calder and Nakafeero 2012). This includes direct effects on recipients (e.g. asset accumulation) from which also other household members tend to benefit, as well indirect secondary benefits for community members (e.g. business owners) and tertiary benefits for the local community (e.g. local availability of goods and markets) (OPM 2016).

\footnotetext{
1 In 2016/17, about $76 \%$ of the poor were living in rural and $24 \%$ in urban areas. Poverty is highest in the Eastern (42\%) and Northern (24\%) region, and at the sub-regional level, poverty rates are much higher in Karamoja (61\%), Bukedi (48\%) and Busoga (42\%) compared to the national average of $27 \%$ (Uganda Bureau of Statistics 2017).

${ }^{2}$ Except for the poorer Karamoja region where the age of entitlement is 60. Also note that in 2020 along with the nationwide expansion, the age of entitlement was raised to the age of 80 .

3 See Hickey and Bukenya (2019) on the political dynamics for expanding the SCG.
} 
Using a qualitative case study design with data collected in four districts and exploiting the local economic differences in which Uganda's SCG is implemented, this paper contributes to the social protection literature in the following ways: First, it provides new qualitative data on the relevance of the SCG for inclusive growth and development in Uganda. Second, the paper provides evidence of the differences in the local impacts of Uganda's SCG programme on access to and participation in economic opportunities in locations with unequal economic structures. It confirms the need to account for the local economic structures when analysing the impacts of SCTs on economic participation. The analysis reveals important spatial differences in the impacts of the programme on the inclusion of recipients and non-recipients in economic processes. While people in areas well-endowed with infrastructure and services are better able to participate in growth processes, people in remote areas remain excluded from economic opportunities or manage to participate only under disadvantaged conditions. This suggests that those living in remote areas are more likely to stay or fall back into poverty in the future compared to people in integrated areas. The implementation of a national SCT programme unintentionally perpetuates inequalities of opportunity, which are present in much of rural Africa. For SCTs to be more inclusive, complementary investments into basic infrastructure in remote areas are necessary.

The remainder of this article is structured as follows: the next section reviews the concept of inclusive growth and development and links it to social protection and spatial inequality. Section three introduces the analytical framework that guides the analysis. This is followed by a section describing the qualitative research methodology before presenting the findings and conclusions.

\section{Inclusive Growth, Social Protection, and Spatial Inequality}

At the heart of the idea of inclusiveness is a concern for equality of opportunity and participation of the poorest, vulnerable and most disadvantaged groups of people (Gupta et al. 2015; Kanbur and Rauniyar 2010; De Haan 2015). Academic debates about inclusiveness tend to distinguish two main concepts: inclusive development and inclusive growth (Gupta et al. 2015). The concept of inclusive development has predominantly been developed in development sociology and political studies and emphasises the importance of social and political participation, empowerment, and relational well-being to achieve equality (Pouw and McGregor 2014). By contrast, the concept of inclusive growth is rooted in development economics and "reflects a welfare approach to development, and refers to creating jobs for the poor to increase their incomes, assets and other social goods, and stimulating competition and aggregate growth in the economy" (Gupta et al. 2015, p. 543). Inclusive growth is thus about the inclusion of people in growth processes. In the words of De Haan (2015, p. 611), it is about "the extent to which people participate in growth, and whether growth is based on the inputs of poor people".

While the idea of inclusive growth has been criticised for being too narrowly focused on achieving economic growth, it is precisely this objective and rationale that underpins much of the current development policy programming. This appears 
particularly so in the area of SCTs, where many interventions are informed by theories of change that predominantly aim at economic (rather than political or social) empowerment. Indeed, social protection advocates have invested considerable efforts into promoting SCTs as part of the inclusive growth agenda and as effective tools to improve people's engagement in livelihood activities, employment or entrepreneurship (Addison and Nino-Zarazua 2012; Barrientos 2012; Alderman and Yemtsov 2014). This narrative has been supported by a large strand of impact evaluations providing evidence on the multiple economic impacts of SCTs (Devereux et al. 2013; Davis et al. 2016). This includes a vast amount of evidence on the positive effects of SCTs on immediate economic outcomes (e.g. the reduction of poverty and food security), as well as positive impacts on participation in economic processes (e.g. livelihood diversification). Moreover, it has been shown that these impacts go beyond the direct effects on recipients and Alderman and Yemtsov 2014). SCTs increase the demand for goods and services, thereby increasing the profits of traders and service providers (secondary effects), and they strengthen local economic structures (e.g. employment opportunities) (tertiary effects).

While the evidence base has supported the integration of social protection into the inclusive growth agenda, it can be argued that distributional concerns, which are at the heart of the development agenda, have received less attention. Social protection evaluations tend to treat the poor as a homogeneous group in order to produce significant results, and there has been little inquiry into intra-group differences. Those studies that take horizontal differences into considerations predominantly focus on indicators like gender or age, which are closely associated with debates around targeting (Seekings 2008; Amuzu et al. 2010; Jones and Holmes 2011). The blind spot in current social protection evaluations is the acknowledgement of location with its local economic structures, which conditions people's ability to participate in growth processes. The economic geography literature (Krugman 1991; Fujita et al. 1999) has early recognised the importance of location in shaping people's ability to participate in economic growth processes, thereby reproducing local economic inequalities (McKay and Perge 2015; World Bank 2009b). Barrientos (2012) acknowledged the conditioning role of factors, such as adequate infrastructure, employment opportunities or local liquidity and trade, in the context of social transfers and argued that local economic structures could constrain the impacts of social transfers on microlevel growth (Barrientos 2012, p. 17). He also emphasises the potentially positive effects of social transfers on the local economic structures by stimulating effective demand (Barrientos 2012).

Despite the acknowledgement of the conditional function of location in the theoretical debates around social transfers, the issue has featured remarkably little in impact evaluations. To our knowledge, the only study which disaggregates the economic impacts of social transfers by geographic factors has been undertaken in Brazil (Rougier et al. 2018). Focusing on changes at the meso level and using a quantitative analysis of municipal-level data, the analysis confirms that the impact of the programme on local economic outcomes is conditioned by the pre-existing local economic structures. However, contrary to their expectations, Rougier et al. (2018) find that remote areas have started a process of catching up with more integrated locations. In rural Africa, despite large spatial inequalities (McKay and Perge 2015), 
the evidence base on the economic impacts of social transfers has so far ignored the inclusiveness of the economic impacts. Uganda is no exception. Existing evaluations of SCTs in Uganda tend to report aggregate economic effects (e.g. in terms of poverty reduction); in case findings are disaggregated, the focus is on differences in terms of targeting mechanisms, vulnerable groups, or household compositions (Ssewanyana 2009; Republic of Uganda et al. 2016; OPM 2015, 2016). If spatial inequalities are considered, the focus is merely on the rural-urban divide or overall regional differences (e.g. Ssewanyana 2009, p. 21). Yet, this level of disaggregation is not granular enough to capture community-level differences. Both regions and rural areas are diverse, with substantial heterogeneity between communities. For example, a rural community may be located along a good road or be centrally located, while other rural communities in the same region are remote and difficult to access. Hence there is need to analyse SCT outcomes at the community level. Moreover, indicators of economic processes and participation, and the different local economic contexts, have largely been neglected.

\section{A Framework Linking Social Transfers with Micro- and Meso-level Growth}

Despite the neglect of intra-group inequalities in many impact studies of social protection, existing studies can help identify the multiple pathways between social protection and economic growth. In order to synthesise the findings, various analytical frameworks have emerged that map how social transfers impact growth through various processes.

Barrientos (2012) offers a framework that links social transfers and economic growth at the micro level focusing on the impacts on recipient and non-recipient households. It suggests that the transmission channel from social transfers to microlevel growth consists of growth-mediating processes and economic outcomes. According to Barrientos (2012), growth-mediating processes refer to intermediate processes that impact the ability to engage in productive activities (e.g. access to credit), while economic outcomes are understood as productive activities. Based on a review of evaluation studies in developing countries, Barrientos (2012) suggests that social transfers improve growth-mediating processes by lifting restrictions on the productive capacity of recipient households, as well as have positive impacts ${ }^{4}$ on the productive activities of recipient households. For non-recipient households, Barrientos (2012) postulates that the effect of SCTs is primarily negative because of the higher tax burden. This, however, ignores circumstances in which social transfers are funded by external donors and the recent evidence on local economic multiplier effects of social transfers (Taylor et al. 2016; Filipski et al. 2015; Ardington et al. 2009; Davies and Davey 2008; Posel et al. 2006).

\footnotetext{
${ }^{4}$ Except for the impact on labour supply, which can either be positive or negative (Barrientos 2012, p. 12).
} 
In contrast to Barrientos (2012), Alderman and Yemtsov's (2014) framework also emphasises the impacts of social transfers on growth at the meso (community) and macro (national) levels. They distinguish four pathways by which social transfers can affect economic growth: (i) improvements in recipient household investments; (ii) mitigating ex-post and ex-ante risk in recipient households; (iii) creating community assets; (iv) relaxing political constraints on policy. By organising their literature review along these four pathways, Alderman and Yemtsov (2014) confirm that at the micro level, social transfers enable recipient households to make investments into productive activities and human capital as well as mitigate risks. At the meso level, social transfers positively influence local economic structures by improving the demand for goods and services available in the community and enhancing the supply of economic opportunities. In terms of impacts at the macro level, Alderman and Yemtsov (2014) suggest that social transfers protect aggregate demand, contribute to social cohesion and enable policy reforms.

This paper focuses on the pathways between SCTs and growth at the micro (households) and meso (community) levels. Our framework distinguishes three types of impacts: primary impacts on recipient households, secondary impacts on providers of goods and services, and tertiary impacts on local economic structures. With respect to recipient households, we follow Barrientos' (2012) suggestion that SCTs influence growth-mediating processes and productive activities. We consider three growth-mediating processes particularly relevant for our study in rural Uganda: access to transportation, telecommunications, and credit. ${ }^{5}$ In terms of productive activities, the focus is on engagement in agricultural wage labour, agricultural production, and non-farm trade. ${ }^{6}$ By strengthening growth-mediating processes and productive activities of recipient households, SCTs stimulate the demand for goods and services. This, in turn, generates positive (secondary) impacts for the providers of transportation, communication, and credit (see Filipski et al. 2015; Ardington et al. 2009; Posel et al. 2006). Through their impact on the productive activities of recipient households, SCTs also affect the providers of labour, agricultural production, and non-farm trade. At the meso level, as noted by Alderman and Yemtsov (2014), SCTs may alter local economic structures by influencing the availability of economic opportunities. In this view, SCTs can generate tertiary benefits for the local community if the increased demand for goods and services translates into better transportation, communication, credit services, agricultural employment opportunities, and supply of agricultural and non-farm goods and services. Figure 1 summarises this framework which will be used to organise and compare our qualitative findings.

\footnotetext{
5 These three growth-mediating processes have been listed in Uganda's Plan for Modernisation of Agriculture (PMA) among the key constraints to rural livelihoods transformation in Uganda (Ocitti 2011; Government of Uganda 2000, 2004).

6 In line with Saith (1992) these three productive activities correspond to the three primary sources of livelihoods in rural economies-namely off-farm, farm and non-farm income sources. According to OPM (2016), these are also the primary forms of livelihood activity of recipients and community members in rural Uganda.
} 

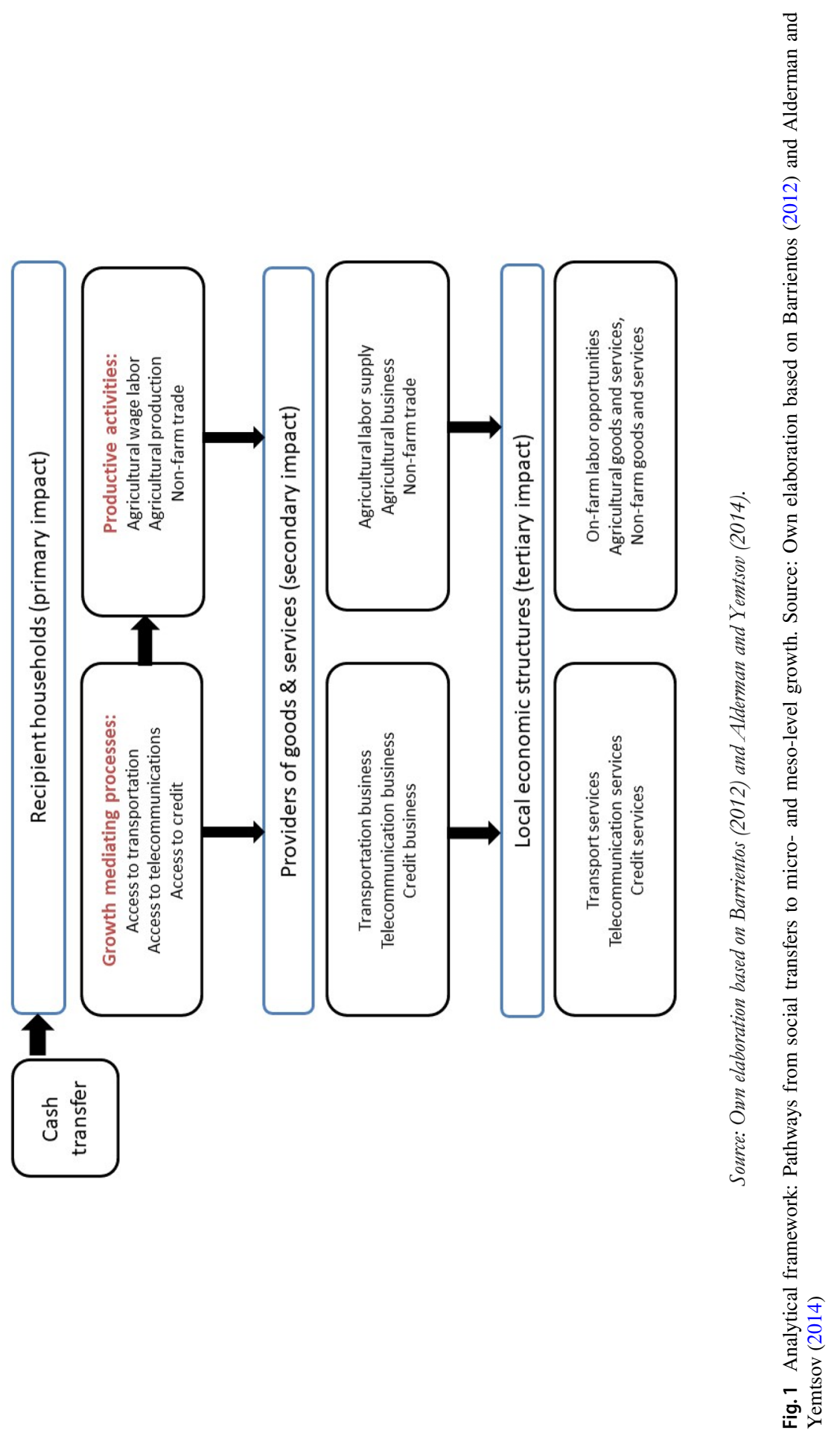

张 
Overall, we expect that SCTs contribute to inclusive growth and development by enabling more people to participate in the processes of economic growth. Yet, we believe this aggregate level perspective disguises important intra-group differences arising from the unequal local economic structures in which SCTs are implemented. Therefore, our proposition is that the location conditions the impacts of SCTs on the economic processes at the micro- and meso-level. Thus, SCTs may contribute to inclusive growth and strengthen the local economy in locations with (pre-existing) favourable productive characteristics. In remote locations, by contrast, less favourable economic conditions are expected to constrain the ability of community members to participate in economic growth processes. Hence, SCTs may unintentionally reproduce pre-existing patterns of exclusion and economic disadvantage.

\section{Research Design and Data}

To unravel the differences in the influence of SCTs on micro- and meso-level growth processes in more and less favourable economic locations in rural Uganda, a multiple case study design (see Yin 2003) was applied that built on two integrated and two remote cases. The main aim of the study was to gain detailed contextual knowledge of the growth processes and their limitations. The contrasting cases aimed at gaining insights into the differences in impacts across locations with different local economic structures, whereas the selection of more than one case each increased the confidence in our findings.

We sampled our cases among the SCG pilot villages, which at the time were rather homogenous in terms of poverty and vulnerability (see Merttens et al. 2016). ${ }^{7}$ The selection took place at the parish level. Districts are subdivided into sub-counties and sub-counties into parishes. Although a parish consists of several villages, it was decided to sample parishes in order to have a sufficiently large population size and likelihood of SAGE beneficiaries for participation in the Focus Group Discussions (FGDs). The selection of parishes was based on the analysis of the SAGE Community Baseline Survey (World Bank Microdata Library 2012b), which collected data on 398 SAGE villages spread across eight districts in Uganda. We only included villages (198) that implemented the Senior Citizens Grant (SCG). Each village was assessed along the following indicators reflecting local economic structures $^{8}$ : availability of a market ${ }^{9}$; bus, taxi or matatu stop; loading point; accessible road throughout the year; the presence of Savings and Credit Cooperatives (SACCOs); a primary school; and a primary health facility. The binary indicators were summed up, and the average value of the villages per parish was used to rank the level of economic integration (Table 1). Given that the analysis provided more than four potential case study parishes, further criteria were set for the final selection: (i)

\footnotetext{
7 With the exception of Karamoja where poverty rates are much higher.

8 The selection of indicators for local economic structures was limited by the SAGE Baseline Community Survey.

9 This includes a permanent/periodic market within one-hour walking distance.
}

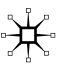


parishes in Karamoja were excluded because of the different SCG targeting criteria (SCG enrolment at age 60 compared to 65 years in other locations); (ii) parishes with a tarmac road closer to its centre were preferred as integrated cases; (iii) remote parishes with an economic advantage compared to other parishes within the same sub-county/district were excluded; (iv) and the selection aimed to be regionally balanced. Based on this assessment, Kisojo and Mukunyu parishes in Kyenjojo district were selected as integrated cases, ${ }^{10}$ and Apoi parish in Apac district and Akurao parish in Katakwi district were selected as remote cases (Table 2).

Kisojo is located in Western Uganda and hosts the sub-county headquarters. Sub-county headquarters tend to have an advantage over other locations in the subcounty in terms of infrastructure and services. Mukunyu was selected because of the tarmac road crossing through the parish's main trading centre compared to other parishes with Murram roads. Tarmac roads attract more traffic and other services. Five of the six parishes with the least access are located in Apac district, of which three are located in Akokoro sub-county. Akokoro parish is not selected because it hosts the sub-county headquarters. Apoi is selected instead of Kungu parish because Kungu parish has ferry transport services that connect Apac district more easily to the Southern districts giving it a slight advantage over Apoi, which does not have the ferry. Akurao was selected mainly for regional balancing. Hence, the four selected case study parishes are drawn from three districts and three out of the four regions: Eastern Uganda (Katakwi), the West (Kyenjojo), and the North (Apac). ${ }^{11}$

This paper is based on two methods of primary data collection: Focus Group Discussions (FGDs) and key informant interviews (KIIs). In total, we conducted 16 FGDs, including in total 161 male and female recipients and non-recipients of the SCG grant across the four locations. ${ }^{12}$ Recipients were sampled randomly based on the local SCG registry. Non-recipients were selected as pairings for the recipients from the third next house of the selected recipient. Hence, the group of nonrecipients did not represent a counterfactual but a group with different and diverse characteristics. Key informant interviews were held with various informants at the district and parish level, including in total 11 local administrators, 3 civil society representatives, 11 local business owners, and 12 financial sector representatives. These interviews were evenly distributed across the four case study sites. Prior to the data collection, the instruments ${ }^{13}$ were tested, and a three-day training for local research assistants was conducted. All interviews and FGDs were audio-recorded, transcribed and analysed using a thematic approach. The transcripts were first organised by case and coded using a double-coding strategy. The analytical strategy first involved a within-case analysis before making comparisons across cases. In each case, the codes from all sources were sorted into themes and then organised

\footnotetext{
${ }^{10}$ Campswahili juu in Moroto, the second most integrated parish was excluded for financial and logistical reasons related to the field work.

11 Fieldwork was conducted between October and December 2016.

12 Each FGD consisted of 9-11 participants.

13 The research protocol has received ethical approval from Mildmay Uganda Research and Ethics Committee (MUREC) (\#REC REF 0409-2016).
} 
Table 1 Distribution of most integrated and remote parishes by sub-county and district. Source own analysis of SAGE community baseline survey

\begin{tabular}{|c|c|c|c|c|c|c|c|c|}
\hline \multirow[t]{2}{*}{ District } & \multirow[t]{2}{*}{ Parish } & \multirow[t]{2}{*}{ Sub-County } & \multirow{2}{*}{$\begin{array}{l}\text { Number of } \\
\text { parishes in } \\
\text { sub-county }\end{array}$} & \multirow[t]{2}{*}{$\begin{array}{l}\text { Sub-county } \\
\text { population }^{\mathrm{a}}\end{array}$} & \multirow{2}{*}{$\begin{array}{l}\text { Estimated } \\
\text { parish } \\
\text { population }^{\text {b }}\end{array}$} & \multicolumn{3}{|c|}{$\begin{array}{l}\text { Number of SCG } \\
\text { recipients }\end{array}$} \\
\hline & & & & & & Total & $M$ & $F$ \\
\hline \multicolumn{9}{|c|}{ Most integrated } \\
\hline Kyenjojo & Mukunyu & Butiiti & 7 & 18,747 & 2678 & 157 & 50 & 107 \\
\hline Moroto & $\begin{array}{l}\text { Campswahili } \\
\text { juu }\end{array}$ & $\begin{array}{l}\text { South Divi- } \\
\text { sion }\end{array}$ & 2 & 8435 & 4218 & 83 & 42 & 41 \\
\hline Kyenjojo & Kisojo & Kisojo & 6 & 22,075 & 3679 & 180 & 65 & 115 \\
\hline Kyenjojo & Rwaitengya & Kisojo & 6 & 22,075 & 3679 & 114 & 45 & 69 \\
\hline \multicolumn{9}{|c|}{ Most remote } \\
\hline Apac & Tel-Oro & Abongomola & 6 & 34,249 & 5708 & 137 & 60 & 77 \\
\hline Apac & Abwong & Abongomola & 6 & 34,249 & 5708 & 254 & 108 & 146 \\
\hline Apac & Akokoro & Akokoro & 8 & 41,935 & 5241 & 165 & 64 & 101 \\
\hline Katakwi & Akurao & Toroma & 5 & 11,825 & 2365 & 170 & 74 & 96 \\
\hline Apac & Apoi & Akokoro & 8 & 41,935 & 5241 & 137 & 63 & 74 \\
\hline Apac & Kungu & Akokoro & 8 & 41,935 & 5241 & 122 & 59 & 63 \\
\hline
\end{tabular}

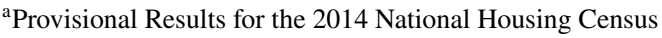

${ }^{b}$ Provisional Results for the 2014 National Housing Census do not present population data by Parish. The estimated parish population is calculated as the sub-county population size divided by the number of Parishes

according to our analytical framework. ${ }^{14}$ The application of the analytical framework to the cases enabled the systematic cross-case analysis. We first compared the cases with similar characteristics and synthesised the findings, and then used the synthesis to compare the findings between integrated and remote locations.

\section{Differences in Local Economic Impacts in Remote and Integrated Rural Uganda}

This section presents and discusses the findings from the qualitative analysis. It follows the six channels proposed by the analytical framework, namely transportation, telecommunication, credit, agricultural wage labour, agricultural production, and non-farm trade. The findings are structured around the differences in economic effects of the SCG on recipients, secondary beneficiaries, and local economic structures.

\footnotetext{
${ }^{14}$ For example, the codes related to credit included: village saving groups, borrowing from others, and purchasing on credit.
} 
Table 2 Key structural characteristics of case study sites. Source own analysis of SAGE community baseline survey

\begin{tabular}{llccl}
\hline Indicator & AKURAO & APOI & KISOJO & MUKUNYU \\
\hline Permanent/periodic market & $0^{\mathrm{a}}$ & $0^{\mathrm{a}}$ & 1 & 1 \\
Bus/taxi/matatu stop & 0 & 0 & 1 & 1 \\
Truck/pick-up present & 0 & 0 & 1 & 1 \\
Credit facility & 1 & 0 & 1 & 1 \\
Primary school & 0.5 & 1 & 1 & 1 \\
Healthcare facility & 1 & 0 & 1 & 1 \\
All year road & 0 & 0 & 1 & 1 \\
Wage agriculture & 3000 & 5000 & 4000 & 4000 \\
Wage non-agriculture, men & 5500 & 4000 & 10,000 & 10,000 \\
Wage non-agriculture, women & 2500 & 4000 & 10,000 & 10,000 \\
\hline
\end{tabular}

${ }^{\mathrm{a}}$ Also not within 60 min walking distance

${ }^{\mathrm{b}}$ No difference between gender

\section{Transportation}

Our integrated and remote case studies show that the SCG increased the ability of recipients to pay for transport, which in turn improved the local motorcycle-taxi business, known as 'boda boda'. This is in line with the findings established by aggregate studies of SCTs (e.g. Davis et al. 2012; Quarles van Ufford et al. 2016; on Uganda, see OPM 2016; Ibrahim and Namuddu 2014). Yet, our cross-case comparison revealed important spatial differences in people's access to transport services which have typically been overlooked in existing studies. Our findings particularly indicate that people in remote locations faced substantial disadvantages. While they were highly dependent on transportation services to participate in trading activities and improve their agricultural production, respondents in remote areas complained that transportation services were fairly limited. For example, a participant of a nonrecipient FGD in a remote area noted that "the problem is that, it is very difficult to access boda-boda. Especially when you are going long distances, you just can't find them ... The boda-bodas are only available on payday. But during usual days, they are very hard to access." 15 Moreover, the cost disadvantage was substantial. Interviewed recipients in remote locations reported spending approximately UGX 10,000 for a $10 \mathrm{~km}$ journey, which is a lot given the UGX 25,000 SCG per month. In contrast, travel distances in integrated areas were shorter and transport costs lower. Some recipients in integrated areas even indicated that they could walk to the next market and save money on transport.

The longer distances and higher dependency on transportation services in remote locations meant that the secondary benefits were particularly high for the drivers of motorcycle taxis operating in remote locations. This was especially the case during

15 Participant 2 of FGD, non-recipient, Apoi parish, Apac district, 18 October 2016. 
paydays when recipients travelled to SCG pay points. In confirmation, a local key informant in a remote location emphasised that "boda-boda drivers make a lot of money during paydays because they pick up elderly persons from their homes, bring them to the pay point, and drive them back to their homes". ${ }^{16}$ These secondary benefits for transport providers are confirmed by an earlier study by Ibrahim and Namuddu (2014). Yet this study ignores important spatial differences that are revealed by our case comparison. Our findings indicate that those secondary benefits were concentrated predominantly in integrated economies. Respondents in remote locations reported that most transport services in their areas were operated by people from integrated areas, who were more likely to afford the cost of buying or hiring a motorcycle. This is in line with Howe (2003), who studied transportation services in rural Uganda and stresses the differences in motorcycle ownership in different locations. In our cases, these differences were particularly observed on paydays, as emphasised by a participant of a non-recipient FGD in a remote study area: "These boda-bodas they are not from here. They just show up on paydays". ${ }^{17}$ This suggests that people in remote locations were unlikely to reap the secondary benefits of the SCG if this required higher-value investments.

Only with regard to tertiary benefits, our cross-case analysis indicates that the SCG improved the availability of motorcycle-taxi services in both integrated and remote locations. These improvements were reported to benefit the entire community and were perceived to be even of greater importance by respondents in remote areas.

\section{Telecommunications}

The findings in our integrated case studies suggest that the SCG increased the use of mobile phones by recipients. Specifically, interviewed recipients in integrated areas reported having invested the SCG in mobile phone credit, mobile phones, ${ }^{18}$ and battery charging. This was also emphasised by key informants, and a business owner noted that "before, some of the old people did not know how to buy or even load air time. But now they do and can communicate anytime. Some of them have even registered their phones on mobile money." 19 While the findings from the integrated case studies corroborate the findings from aggregate studies of SCTs (e.g. Davis et al. 2012; Quarles van Ufford et al. 2016; on Uganda, see OPM 2015; Ibrahim and Namuddu 2014), our remote case studies reveal a different picture. In remote areas, people were largely excluded from mobile phone network coverage, which constrained their use of mobile phones. For example, an informant from the business

\footnotetext{
16 Interview with key informant from local administration 1, Akurao parish, Katakwi district, 03 November 2016.

17 Participant 1 of FGD, non-recipient, Apoi parish, Apac district, 18 October 2016.

18 Note that until 2016, Uganda's SCG scheme was delivered using a mobile money service whereby all recipients were provided with a SIM card which was used as a mobile money account (Bukuluki and Watson 2012).

19 Interview with key informant from business sector, Kisojo parish, Kyenjojo district, 26 October 2016.
} 
sector explained: "There is not much change [in the use of mobile phone services by recipients] ... the network of both MTN and airtel are still poor. That's why I said not much changed." 20

The difference in mobile phone usage between integrated and remote areas translated into unequal secondary benefits for telecommunication businesses. In integrated locations, respondents indicated that providers of mobile phone credit, charging services, and repairs benefited indirectly from the SCG. These positive findings are generally in line with the SCT evidence base (e.g. Davis et al. 2012; Quarles van Ufford et al. 2016) that tends to ignore the limitations in remote areas. Our remote case studies reveal that the limited mobile phone network coverage inhibited mobile phone businesses to flourish. As such most respondents in remote areas felt that secondary benefits hardly occurred.

The disparities in telecommunication services between remote and integrated areas were further mirrored at the tertiary level. In integrated locations, respondents indicated that the SCG improved the availability of mobile phone services and, in particular, the mobile phone credit and charging services in their communities. In contrast, the fundamental structural constraint in remote locations meant that tertiary impacts seemed largely absent. Respondents in remote areas felt strongly disadvantaged, and many interviewees complained about the poor network coverage and the limited and expensive mobile phone credit and charging services in their communities. The comparison of tertiary impacts between integrated and remote areas suggests that the SCG contributed to widening inequalities in access to communication services.

\section{Credit}

The case comparison does not indicate major differences in access to credit between integrated and remote cases. As such, they largely confirm the findings of earlier studies, suggesting that SCTs can improve the saving capacity of recipient households and enable access and use of credit services (Barrientos 2012; Alderman and Yemtsov 2014). Specifically, it corroborates existing data from Uganda (OPM 2016) that indicates that the SCG enabled recipients to save more, access small loans through informal village saving groups, enhance their creditworthiness, and ability to buy on credit. ${ }^{21}$ Our findings also corroborate earlier data (OPM 2016). that established that recipients were largely not able to access semi-formal credit services $^{22}$ (e.g. SACCOs), which offer better interest rates and safer credit and saving conditions. Importantly, our comparison reveals that this was the case in both

\footnotetext{
20 Interview with key informant from business sector, Apoi parish, Apac district, 19 October 2016.

21 According to OPM (2016), the proportion of households with cash savings increased by 19 percentage points, the proportion of households participating in Village Savings and Loans Associations (VSLAs) by 8 percentage points and the proportion of households purchasing on credit increased by 10 percentage points.

22 In line with Johnson and Nino-Zarazua (2011), semi-formal credit services are defined as those services with certain reporting requirements (e.g. consumer finance companies, credit card companies, savings and credit cooperatives (SACCOs)).
} 
integrated and remote areas. While we expected this for remote cases due to the absence of these services, we found that most recipients in integrated locations remained excluded from the semi-formal sector mainly because of unattainable membership conditions ${ }^{23}$ (e.g. relatively high costs for opening a SACCO bank account). In confirmation, a non-recipient participating in an FGD in an integrated area emphasised that "SACCOs normally helps businessmen who have big volumes of goods or those who are expanding. But the elderly have to use village saving group because their business is small." 24

The increased use of informal credit services by recipients resulted in important secondary benefits for other users of these services in integrated and remote cases, and a key informant in a remote study area stated that the participation of recipients in informal saving groups "makes access to credit easier for all members, because we have more money [available for borrowing]". ${ }^{25}$ Other respondents also emphasised the reduction of the risk of providing loans to older people. The improved access to informal credit services by recipients and the improved credit conditions translated into an increase in village saving groups in integrated and remote cases. This generated more informal opportunities to participate in borrowing and saving for the wider community. Our integrated case studies further show that the SCG did not increase semi-formal or formal credit services, thereby corroborating the findings of aggregate earlier studies (e.g. OPM 2016).

\section{Agricultural Wage Labour}

Our case studies in integrated and remote locations indicate that recipients invested the SCG into hiring agricultural labour (e.g. for ploughing or weeding) and thereby confirm aggregate study findings (e.g. OPM 2016; Ibrahim and Namuddu 2014). But our comparison also reveals important differences, particularly regarding the cost of labour across the different locations. In remote areas, it was reported that the increased demand for labour on subsistence or semi-subsistence farms increased the price for labour, and a local administrator noted that "wage labour has become more expensive. The amount has increased by 500 UGX." 26 While all respondents from remote areas confirmed this, respondents from integrated areas did not share the same experience. This suggests that recipients in integrated areas had an advantage in hiring agricultural labour at a cheaper price.

The increased demand for labour by recipients tended to be associated with a reduced engagement of recipients in hard agricultural work. Our findings indicate that recipients worked less on their own farms, and this finding was corroborated by

\footnotetext{
${ }^{23}$ For example, for SACCOs this includes the following conditions: to service a loan on a monthly basis; to pay an initial 38,000 UGX to open their SACCO account; and to own fixed assets that can act as collateral.

${ }^{24}$ Participant 6 of FGD, non-recipient, Mukunyu parish, Kyenjojo district, 27 October 2016.

${ }^{25}$ Interview with key informant from financial sector, Akurao parish, Katakwi district, 03 November 2016.

${ }^{26}$ Interview with key informant from local administration 2, Akurao parish, Katakwi district, 03 November 2016.
} 
a previous study (OPM 2016). Moreover, it was found that recipients also worked less on other people's farms. While this was generally the case in both integrated and remote locations, our case comparison also indicated that the limited economic opportunities in remote areas made recipients more dependent on agricultural wage labour in times of need than recipients in integrated areas. The favourable productive environment allowed recipients in integrated areas to engage in less physically demanding wage labour (e.g. petty trade) as a means of coping.

Our findings further suggest that the overall increased demand for and reduced supply of labour by recipients resulted in important secondary benefits for labourers in integrated and remote cases. For example, a non-recipient participating in a FGD in an integrated area noted that there are "more labour opportunities because old people have stopped competing with us", ${ }^{27}$ and another participant stated that "there are many casual labourers in our parish because they know there is money, and jobs are available".28 This confirms the findings established by aggregate studies that SCTs increase labour opportunities (e.g. Alderman and Yemtsov 2014; Davis et al. 2016). Beyond these overall effects, our case studies also suggest that the price of labour had increased in remote locations, and a key informant in a remote area emphasised that "non-recipients get more work and more pay". ${ }^{29}$ The reported increase in the price for labour in remote areas seems to suggest an advantage for labourers in remote areas. Yet, these findings need to be read against the unequal opportunities between remote and integrated areas whereby job seekers in remote areas were merely able to engage in lower-paid labour opportunities on subsistence or semi-subsistence farms. By contrast, labourers in integrated areas could take up opportunities for higher-paid employment on commercial tea plantations, which remained unavailable in remote communities.

\section{Agricultural Production}

Our case studies suggest that the scheme allowed recipients to cultivate more land and increase their agriculture production through investments into seeds, agrochemicals, and labour. This, in turn, increased agricultural outputs and enabled recipients to improve the food security of their households and, at times, sell surpluses. This is generally in line with findings from aggregate studies that confirming that SCT can help poor households to overcome barriers to entry into semi-subsistence production by alleviating liquidity constraints and increase the certainty needed for making investments (Tirivayi et al. 2016; Barrientos 2012; on Uganda, OPM 2016; Ibrahim and Namuddu 2014). Yet, the case comparison revealed that the limited access to markets in remote areas put recipients at a disadvantage compared to recipients in integrated locations. For example, recipients in remote locations reported that they had to travel long distances at a relatively high cost to purchase agricultural inputs

\footnotetext{
27 Participant 2 of FGD, non-recipient, Kisojo parish, Kyenjojo district, 25 October 2016.

28 Participant 3 of FGD, non-recipient, Kisojo parish, Kyenjojo district, 25 October 2016.

${ }^{29}$ Interview with key informant from local administration 2, Akurao parish, Katakwi district, 03 November 2016.
} 
and sell their produce. In integrated areas, recipients appeared much better positioned to participate in markets that were available at a relatively short distance.

The limited availability of agricultural markets and input sellers in remote areas suggests an outflow of money from more remote to more integrated areas. Much of the spillover was captured by people living in more integrated areas who benefited from both the increased demand by recipients from more integrated areas and more remote areas. This is illustrated in the following quote of an input seller in an integrated area:

This I say with a lot of confidence, the demand [for inputs] is higher. Before, my customers were not the elderly but middle-aged men and the youth. When SAGE came, the elderly became more interested in farming because they wanted to make use of the money. ${ }^{30}$

Interestingly, the increase in demand by recipients in remote areas did not improve the availability of input sellers in remote locations, and a non-recipient participating in a FGD confirmed that "there are no new agricultural services in the parish or sub-county". ${ }^{31}$ Tertiary benefits were merely observed in integrated areas where input shops already existed before the arrival of the SCG. Specifically, the findings suggest an increase in the availability of agricultural inputs in integrated areas due to the increased demand by recipients from remote and integrated areas. This implies that the SCG indirectly contributed to exacerbating the differences in the availability of agricultural input shops between remote and integrated areas.

\section{Non-farm Trade}

Our findings indicate that the SCG had positive primary impacts on non-farm trade in all case studies as it allowed recipients to buy low-value items (e.g. selling brew, salt, millet flour, paraffin, or soap) and sell them for a small profit. This upholds findings from existing studies that indicate that SCTs enabled recipients to start up or expand small retail businesses (e.g. Fisher et al. 2017; on Uganda, see OPM 2016; Ibrahim and Namuddu 2014). Moreover, the increased demand by recipients was seen to have improved the profits of non-recipient vendors and the vibrancy of local markets, led to the opening of new temporary markets on SCG paydays, and brought goods closer to communities. Beyond this, our findings also reveal important spatial disparities as recipients in integrated areas could engage in more lucrative petty trading than recipients in remote areas. This was because they had access to larger markets where they could buy higher-value goods at relatively low prices (e.g. mats and baskets) and sell them at local trading centres for a profit. Most recipients in remote areas were excluded from accessing larger markets and thus opted for selling lower-value goods (e.g. boiled eggs and cassava chips).

\footnotetext{
30 Interview with key informant from business sector, Mukunyu parish, Kyenjojo district, 28 October 2016.

31 Participant 1 of FGD, non-recipient, Akurao parish, Katakwi district, 02 November 2016.
}

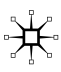


In terms of secondary impacts, our cross-case analysis suggests strong benefits for non-recipients who worked as vendors in both remote and integrated areas. Similar to the findings of other studies (e.g. OPM 2016), vendors reported to have augmented their profits and noted the increased purchasing power and demand by recipients. For example, a local administrator emphasised that "more people have opened shops to target these recipients of the SCG programme", 32 and a key informant from the finance sector stated that "before the cash transfer, old people did not buy things from the market. But since the cash transfer, the number of customers increased because more elderly are buying." 33

Given the overall rise in demand by recipients, it is not surprising that there are no indications that the enhanced participation of recipients in petty trade led to more competition among vendors. Our findings suggest important improvements in available trading facilities., and respondents in integrated and remote areas indicated that "the markets have expanded and shop keepers increase their stock when its payday", 34 "shops make a lot of sales, hawkers have come in place with new commodities", 35 and "there is an increment in the volume of goods". ${ }^{36}$ Our case studies also confirm the emergence of new temporary markets on SCG paydays customised to the specific demand of SCG recipients (e.g. clothes, blankets and meat). While these findings suggest that community members in both integrated and remote areas benefited from the tertiary impacts of the SCG scheme, the improvements of local trading centres were perceived to be particularly important for community members in remote areas since it meant that goods were brought closer to the communities.

\section{Conclusion}

The inclusive growth and development agenda identifies equality of opportunity as a key goal for sustainable poverty reduction and economic development. It emphasises the importance of providing economic opportunities to people who have been excluded from participating in economic growth processes. Social protection in the form of SCTs has been acknowledged as contributing to this objective, and the positive economic impacts of these interventions have been empirically demonstrated by a range of impact studies. Yet, most of these studies focus on the poor as a homogenous group which hides important intra-group inequalities that can improve livelihoods for some while generating exclusion and disadvantages for others. Given the primary motivation to report positive impacts, aggregate level studies fail to adequately identify the sub-groups that remain deprived of participating in the economic growth processes generated by the implementation of SCTs. This is

\footnotetext{
32 Interview with key informant from local administration 2, Akurao parish, Katakwi district, 03 November 2016.

33 Interview with key informant from financial sector, Mukunyu parish, Kyenjojo district, 28 October 2016.

34 Participant 5 of FGD, non-recipient, Mukunyu parish, Kyenjojo district, 27 October 2016.

35 Interview with key informant from business sector, Kisojo parish, Kyenjojo district, 26 October 2016.

36 Participant 3 of FGD, non-recipient, Apoi parish, Apac district, 18 October 2016.
} 
particularly so in terms of inequalities in local economic structures, which are likely to influence the inclusiveness of the impacts of SCTs on economic participation.

Therefore, this article aimed at filling this gap by examining the intra-group inequalities in the economic impacts of SCTs in Uganda, drawing on new qualitative data collected in the case study districts of Kyenjojo, Apac, and Katakwi in which Uganda's SCG scheme has been implemented. To unravel the differences in the economic impacts in the different locations, we revised and extended Barrientos' (2012) framework by acknowledging the positive impacts for non-recipients as a result of local multiplier effects and the identification of three impact layers. The advantage of the qualitative comparative case study approach is its ability to provide detailed insights into the particularities of specific phenomena. Although the findings may not be generalisable for the entire population, they are transferable to similar settings. Districts like the ones selected for this case study are typical not only for Uganda but also for other countries in sub-Saharan Africa with high levels of spatial inequality (Beegle et al. 2016), which are characterised by unequal access to infrastructure and services (e.g. transportation, financial services, and markets) that affect the economic opportunities of people and their ability to move out of poverty (World Bank 2012a; DRT 2013). A limitation of this study is the focus on the SCG, which targets the elderly population. It would be interesting to compare the local economic impacts with SCTs targeted at other vulnerable groups and with alternative social protection interventions, such as public work programmes or inkind transfers.

From an aggregate perspective, our case studies from rural Uganda support the argument made by many evaluation studies that SCTs contribute to inclusive growth and development by including more people in growth processes. However, our cross-case comparison reveals that not everybody benefits equally. We find that people living in remote locations have been constrained in their ability to participate in economic growth processes. The constraints were often the result of limited economic structures available in remote communities. The poor economic environment meant that people were either largely excluded from economic opportunities (e.g. engaging in mobile phone business in locations without network coverage) or participating under disadvantaged conditions (e.g. engaging in low-profit non-farm trade). By contrast, people living in integrated rural Uganda were in a much better position to take part in the economic opportunities that the SCG generated. The difference in the impacts of the SCG on economic participation in remote and integrated rural Uganda suggests that the scheme has unintentionally reinforced spatial patterns of economic exclusion and disadvantages in rural areas. The SCG has contributed to further improve the available economic structures in integrated areas. As this was rarely the case in remote areas, the SCG might have widened the gap in local economic structures between integrated and remote areas. As a result, people in remote rural areas remain more likely to stay or fall back into poverty in the future than people in integrated areas. This suggests that the SCGs ability to contribute to inclusive growth and better economic opportunities for all depends on the locally available economic structures.

While there is little doubt that SCTs have positive local economic impacts, for SCTs to meet the challenge of inclusiveness in contexts of unequal economic 
structures, there is need for a more holistic and coordinated approach to social protection programming that is sensitive to the structural contexts. First, this requires policy studies-which inform design choices - to go beyond the comfort zone of an aggregate perspective that overly emphasises the positive impacts of these interventions. SCT policies need to be formulated based on a more nuanced understanding of the differences and obstacles to the participation of rural people in growth processes and take into consideration not only individual characteristics of recipients (such as gender and age) but also community-level factors (such as local trade and employment opportunities). Second, there is need to treat different locations differently by initiating complementary development interventions that balance the "playing field' in which interventions are implemented. This can take different forms depending on the contexts and may include interventions that improve local trade, transport infrastructure or credit services. Finally, such a holistic approach is likely to require closer collaboration across sectoral Ministries as well as closer cooperation with local administrators in rural areas.

Acknowledgements This research has been part of the research agenda of the Knowledge Platform Inclusive Development Policies and funded by the Ministry of Foreign Affairs of the Netherlands through NWO-WOTRO (W08.390.003). We thank our fieldwork teams and all respondents in Uganda who generously shared their time, knowledge and experiences. We also thank the Expanding Social Protection (ESP) Secretariat, and in particular Jane Namuddu, for supporting this research. Finally, we thank Armando Barrientos and conference participants in Brussels and Kampala for their useful comments to earlier versions of this paper.

\section{Declarations}

Conflict of interest On behalf of all authors, the corresponding author states that there is no conflict of interest.

Open Access This article is licensed under a Creative Commons Attribution 4.0 International License, which permits use, sharing, adaptation, distribution and reproduction in any medium or format, as long as you give appropriate credit to the original author(s) and the source, provide a link to the Creative Commons licence, and indicate if changes were made. The images or other third party material in this article are included in the article's Creative Commons licence, unless indicated otherwise in a credit line to the material. If material is not included in the article's Creative Commons licence and your intended use is not permitted by statutory regulation or exceeds the permitted use, you will need to obtain permission directly from the copyright holder. To view a copy of this licence, visit http://creativecommons.org/licen ses/by/4.0/.

\section{References}

Addison, T., and M. Nino-Zarazua. 2012. What is Inclusive Growth? Presentation at Nordic-Baltic MDB meeting, Helsinki, 25 January.

Alderman, H., and R. Yemtsov. 2014. How Can Safety Nets Contribute to Economic Growth? The World Bank Economic Review 28 (1): 1-20.

Amuzu, C., N. Jones, and P. Pereznieto. 2010. Gendered Risks, Poverty and Vulnerability in Ghana: To What Extent is the LEAP Cash Transfer Programme Making a Difference, ODI Report. London: Overseas Development Institute. 
Ardington, C., A. Case, and V. Hosegood. 2009. Labor Supply Responses to Large Social Transfers: Longitudinal Evidence from South Africa. American Economic Journal: Applied Economics 1 (1): $22-48$.

Barrientos, A. 2012. Social Transfers and Growth: What Do We Know? What Do We Need to Find Out? World Development 40 (1): 11-20.

Bastagli, F., J. Hagen-Zanker, L. Harman, G. Sturge, V. Barca, T. Schmidt, and L. Pellerano. 2016. Cash Transfers: What Does the Evidence Say? A Rigorous Review of Impacts and the Role of Design and Implementation Features. London: Overseas Development Institute.

Beegle, K., L. Christiaensen, A. Dabalen, and I. Gaddis. 2016. Poverty in a Rising Africa, Africa Poverty Report. Washington: World Bank.

Bukuluki, P., and C. Watson. 2012. Transforming Cash Transfers: Beneficiary and Community Perceptions of the Senior Citizen Grant (SCG) in Uganda. London: Overseas Development Institute.

Calder, R., and A. Nakafeero. 2012. Uganda's Expanding Social Protection Programme. Gender Situational Analysis. Development Pathways Report. London: Development Pathways.

Davies, S., and J. Davey. 2008. A Regional Multiplier Approach to Estimating the Impact of Cash Transfers on the Market: The Case of Cash Transfers in Rural Malawi. Development Policy Review 26 (1): 91-111.

Davis, B., S. Handa, N. Hypher, N. Winder Rossi, P. Winters, and J. Yablonski. 2016. From Evidence to Action: The Story of Cash Transfers and Impact Evaluation in Sub-Saharan Africa. Oxford: Oxford University Press.

Davis, B., M. Gaarder, S. Handa, and J. Yablonski. 2012. Evaluating the Impact of Cash Transfer Programs in Sub-Saharan Africa: An Introduction to the Special Issue. Journal of Development Effectiveness 4 (1): 1-8.

De Haan, A. 2015. Inclusive Growth: Beyond Safety Nets? European Journal of Development Research 27: 606-622.

Devereux, S., K. Roelen, C. Béné, D. Chopra, J. Leavy, and J.A. McGregor. 2013. Evaluating Outside the Box: An Alternative Framework for Analysing Social Protection Programmes. IDS Working Paper No. 431. Brighton: Institute of Development Studies.

Doyle, A., N. Hudda, M. Marzi. 2021. Towards Shock-Responsive Social Protection: Lessons from the COVID-19 Response in Uganda. OPM report. Oxford: Oxford Policy Management.

DRT. 2013. The 2nd Chronic Poverty Report-Uganda: Is Anybody Listening? DRT report. Kampala: Development Research and Training and Chronic Poverty Advisory Network.

Filipski, M.J., J.E. Taylor, K.E. Thome, and B. Davis. 2015. Effects of Treatment Beyond the Treated: A General Equilibrium Impact Evaluation of "',' 'Lesotho's", , Cash Grants Program. Agricultural Economics 46 (2): 227-243.

Fisher, E., R. Attah, V. Barca, C. O’Brien, S. Brook, J. Holland, A. Kardan, S. Pavanello, and P. Pozarny. 2017. The Livelihood Impacts of Cash Transfers in Sub-Saharan Africa: Beneficiary Perspectives from Six Countries. World Development 99: 299-319.

Fujita, M., P. Krugman, and A.J. Venables. 1999. The Spatial Economy. Cities, Regions and International Trade. Cambridge: The MIT Press.

Government of Uganda. 2000. Plan for Modernisation of Agriculture: Eradicating Poverty in Uganda. Kampala: Government of Uganda.

Government of Uganda. 2004. Plan for the Modernisation of Agriculture (PMA) Annual Report 2003/2004. Kampala: Ministry of Finance, Planning and Economic Development.

Gupta, J., N.R. Pouw, and M.A. Ros-Tonen. 2015. Towards an Elaborated Theory of Inclusive Development. The European Journal of Development Research 27 (4): 541-559.

Howe, J. 2003. Filling the Middle. Uganda's Appropriate Transport Services. Transport Reviews 23 (2): $161-176$.

Ibrahim, F., and J. Namuddu. 2014. Uganda's Senior Citizen Grant: Flow-on Effects of Cash Transfers in Kiboga and Kyenjojo Districts, ESPP Report. Kampala: Expanding Social Protection Programme.

Jones, N., and R. Holmes. 2011. Why is Social Protection Gender-Blind? The Politics of Gender and Social Protection. IDS Bulletin 42 (6): 45-52.

Kanbur, R., and G. Rauniyar. 2010. Conceptualising Inclusive Development: With Applications to Rural Infrastructure and Development Assistance. Journal of the Asia Pacific Economy 15 (4): 437-454.

Krugman, P. 1991. Increasing Returns and Economic Geography. The Journal of Political Economy 99 (3): 483-499. 
McKay, A., and E. Perge. 2015. Spatial Inequality and Its Implications for Growth-Poverty-Reduction Relations. In Economic Growth and Poverty Reduction in Sub-Saharan Africa: Current and Emerging Issues, ed. A. McKay and E. Thorbecke, 1-19. Oxford: Oxford University Press.

Merttens, F., E. Sindou, R. Attah, and C. Hearle. 2016. Evaluation of the Uganda Social Assistance Grant for Empowerment (SAGE) Programme: Programme Operations Performance. Endline Final Report. Oxford: Oxford Policy Management.

MGLSD. 2015. National Social Protection Policy. Kampala: Ministry of Gender, Labour and Social Development.

MGLSD. 2016. Senior Citizens Grant (SCG) Operational Manual. Kampala: Ministry of Gender, Labour and Social Development.

Ocitti, S.J. 2011. Nucleated Villages: A Strategy for Rural Development in Uganda, Africa. Bloomington: AuthorHouse.

OPM. 2015. Evaluation of the Uganda Social Assistance Grants for Empowerment (SAGE) Programme: Impact after one year of programme operations 2012-2013, OPM Report. Oxford: Oxford Policy Management.

OPM. 2016. Evaluation of the Uganda Social Assistance Grants for Empowerment (SAGE) Programme: Impact After Two Years of Programme Operations 2012-2014, Final Report. Oxford: Oxford Policy Management.

Posel, D., J.A. Fairburn, and F. Lund. 2006. Labour Migration and Households: A Reconsideration of the Effects of the Social Pension on Labour Supply in South Africa. Economic Modelling 23: 836-853.

Pouw, N.R.M., and J.A. McGregor. 2014. An Economics of Wellbeing. How Would Economics Look Like if It Were Focussed on Human Wellbeing? IDS Working Paper 436. Brighton: Institute of Development Studies.

Quarles van Ufford, P., C. Harland, S. Michelo, G. Tembo, K. Toole, and D. Wood. 2016. The Role of Impact Evaluation in the Evolution of Zambia's Cash Transfer Programme. In From Evidence to Action: The Story of Cash Transfers and Impact Evaluation in Sub-Saharan Africa, ed. B. Davis, S. Handa, N. Hypher, N. Winder Rossi, P. Winters, and J. Yablonski. Oxford: Oxford University Press.

Ravallion, M. 2009. Economic Growth and Poverty Reduction: Do Poor Countries Need to Worry about Inequality? In The Poorest and Hungry, ed. J. Von Braun, R. Vargas Hill, and R. Pandya-Lorch. Washington: International Food Policy Research Institute.

Republic of Uganda. 2015. The National Development Plan (NDPII) 2015/16-2019/20. Kampala: Republic of Uganda.

Republic of Uganda, EPRI and UNICEF. 2016. Social Protection: Investment Case, Joint report Nov 16. Kampala: Ministry of Gender, Labour, and Social Development.

Rougier, E., F. Combarnous, and Y. Fauré. 2018. The "Local Economy” Effect of Social Transfers: An Empirical Assessment of the Impact of the Bolsa Família Program on Local Productive Structure and Economic Growth. World Development 103 (2018): 199-215.

Saith, A. 1992. The Rural Non-Farm Economy: Processes and Policies. Geneva: International Labour Office, World Employment Programme.

Seekings, J. 2008. Deserving Individuals and Groups: The Post-apartheid State's Justification of the Shape of South Africa's System of Social Assistance. Transformation: Critical Perspectives on Southern Africa 68: 28-52.

Ssewanyana, S.N. 2009. Growth, inequality, cash transfers and poverty in Uganda, IPCIG report No. 19. Brasilia: International Policy Centre for Inclusive Growth (IPCIG).

Taylor, J.E., K. Thome, and J. Filipski. 2016. Local Economy-Wide Impact Evaluation of Social Cash Transfer programmes. In From Evidence to Action: The Story of Cash Transfers and Impact Evaluation in Sub-Saharan Africa, ed. B. Davis, S. Handa, N. Hypher, N. Winder Rossi, P. Winters, and J. Yablonski. Oxford, UK: Oxford University Press.

Tirivayi, N., M. Knowles, and B. Davis. 2016. The Interaction Between Social Protection and Agriculture: A Review of Evidence. Global Food Security 10: 52-62.

Uganda Bureau of Statistics. 2017. Uganda National Household Survey 2016/17. Kampala: Uganda Bureau of Statistics.

World Bank. 2009a. What is Inclusive Growth? (World Bank Note. 10 February), http://siteresources. worldbank.org/INTDEBTDEPT/Resources/468980-1218567884549/WhatIsInclusiveGrowth2008 1230.pdf. Accessed 4 Sept 2018.

World Bank. 2009b. Reshaping Economic Geography, World Development Report 2009. Washington: World Bank. 
World Bank. 2012a. Uganda: Promoting Inclusive Growth: Transforming Farms, Human Capital and Economic Geography, World Bank Synthesis Report. Washington: World Bank.

World Bank Micro data Library. 2012b. Social Assistance Grants for Empowerment Programme 2012, Evaluation Baseline Survey, http://microdata.worldbank.org/index.php/catalog/2652. Accessed 25 July 2016.

Yin, R.K. 2003. Case Study Research: Design and Methods, 3rd ed. Thousand Oaks, CA: Sage.

Publisher's Note Springer Nature remains neutral with regard to jurisdictional claims in published maps and institutional affiliations. 